\title{
Organo-modified montmorillonite/poly( $\varepsilon$-caprolactone) nanocomposites prepared by melt intercalation in a twin-screw extruder
}

\author{
Sami Labidi, Nathalie Azema, Didier Perrin*, José-Marie Lopez-Cuesta \\ Centre des Matériaux de Grande Diffusion (CMGD), Ecole des Mines d'Alès, 6, avenue de Clavières, 30319 Alès Cedex 9, France
}

A B S T R A C T

Nanocomposites based on biodegradable poly( $\varepsilon$-caprolactone) organo-modified clay have been prepared by melt intercalation using a twin-screw extruder. The screw configuration developed allowed us to obtain an intercalated/exfoliated nanocomposite structure using a modified montmorillonite containing no polar groups, in contrast to previous work using mainly alkyl ammonium containing hydroxyl polar groups in poly( $\varepsilon$-caprolactone). Montmorillonite nanocomposites were prepared using a specific extrusion profile from a $30 \mathrm{wt} \%$ masterbatch of organo-modified clay, which was then diluted at 1,3 and $5 \%$. Intercalated and/or exfoliated nanocomposites structures were assessed using rheological procedures and confirmed by transmission electron microscopy analysis. Mechanical and thermal properties were found to be strongly dependent on morphology and clay percentage. Crystallinity was only slightly affected by the clay addition. Effect of exfoliation on Young's modulus and thermal stability was investigated. Young's modulus increased significantly and onset degradation temperature measured by TGA was significantly reduced for an exfoliated nanocomposite composition containing 5 wt\% organoclay.

Keywords:

Nanocomposites

$\varepsilon-\mathrm{PCL}$

Montmorillonite

Thermal stability

Young's modulus

Exfoliation

\section{Introduction}

Polymer/layered silicate nanocomposites are a new class of materials with enhanced properties compared to filled composites containing mineral particles in the micron range.

It is well known that a few amount of nanofillers, particularly layered silicates, typically $1-5 \mathrm{wt} \%$, depending on the morphologies obtained for the composite, are able to improve several functional properties, such as Young's modulus and tensile stress, permeability to gases and solvents, thermal stability and flame retardancy [1].

The most commonly used clay for polymer/clay nanocomposites is organo-modified montmorillonite (OMMT). When OMMT is dispersed within the matrix, several specific morphologies, intercalation, exfoliation or combinations of both, are possible. In contrast to morphologies corresponding to microcomposites, only these morphologies allow mechanical, thermal properties and fire behaviour to be notably improved.

Three main methods are used to prepare polymer/clay nanocomposites: melt intercalation, exfoliation-adsorption and in situ polymerization [2]. Melt intercalation is becoming a widely used process for the preparation of nanocomposites. The process is

\footnotetext{
* Corresponding author. Fax: +3346678 5365 .

E-mail address: didier.perrin@ema.fr (D. Perrin).
}

usually carried out using an internal mixer or an extruder. The ability to disperse OMMT, to obtain intercalation and/or exfoliation by delamination of the layered silicates strongly depends on the extruder nature (single or twin-screw) and especially its screw configuration (shear rate).

Nowadays, for environmental concerns, a growing attention has been focused on biodegradable and biocompatible synthetic polymers, such as PCL (poly( $\varepsilon$-caprolactone)). PCL is biodegradable aliphatic polyester known for its use in medical devices, pharmaceutical controlled release systems and biodegradable packaging [3]. It is a crystallisable polymer with a crystallinity around $45 \%$, a glass-transition temperature around $-60^{\circ} \mathrm{C}$ and a melting point near $60^{\circ} \mathrm{C}$.

Performances of this polymer can be greatly enhanced by dispersion of a small amount of layered silicates. Nanocomposites based on PCL have been widely reported [4-15].

Many works have investigated the influence of the methods of silicate modification and processing conditions on the morphology of nanocomposites and so, on their final properties. Overall, their goal was to increase the performance of mechanical and thermal properties of PCL.

Luduena and co-workers have studied the influence of exfoliation-adsorption and melt intercalation methods on the mechanical performance of a methyl tallow bis-2-hydroxyethyl, quaternary ammonium modified montmorillonite [14]. For exfoliationadsorption, the nature of the solvent used and the operating 
conditions were found to have an influence on morphology and consequently on final properties. In the case of melt intercalation by intensive mixing, a higher clay dispersion degree was achieved up to $5 \mathrm{wt} \%$ due to the shear forces and the resultant mechanical properties were found higher to those obtained by solvent casting.

Melt intercalation using a two roll mixer was presented as a relevant method by Lepoittevin and co-workers [9], leading to a good dispersion of montmorillonites modified using hydrogenated tallow alkyl based quaternary ammonium cations. Stiffness and thermal stability improved with the filler loading up to a content of $5 \mathrm{wt} \%$.

In situ polymerization and melt intercalation appeared to be more convenient to achieve intercalated/exfoliated structures. Several authors obtained intercalated/exfoliated nanocomposites using in situ polymerization [5-7,12,13,16]. The extent of exfoliation was controlled by the polarity of the organo-modified clay. Only intercalated structures could be obtained using OMMT with nonpolar groups in the ammonium ion modifier [5].

A similar behaviour was found by Zheng et al. [13] using Cloisite $15 A^{\circledR}$. However, they obtained exfoliated structure, also using Cloisite $30 \mathrm{~B}^{\circledR}$.

Melt intercalation methods were carried out, using a roller mixer $[8-10,13,14]$ or an extruder. For PCL nanocomposites, no previous works were made using an extruder at a pilot-scale. A DSM microextruder was used by Homminga et al. [3,15], leading to intercalated/ exfoliated morphologies. Once again, exfoliation depended on the polarity of the organophilic groups of the ammonium ion used as modifier [9]. Better mechanical performances of PCL were found using melt intercalation compared to adsorption-exfoliation method [14]. Thermal stability was also improved by using this method compared to in situ polymerization [13].

As a matter of fact, compatibilisation between PCL and montmorillonite seems to be the key issue, allowing nanocomposite morphologies to be achieved. It can be supposed that montmorillonite should be sufficiently polar (due to the nature of the groups of organo-modifier) to be well dispersed.

Nevertheless, the influence of the mixing process on the resulting morphologies has also to be taken into account for melt intercalation methods, particularly by twin-screw extrusion. Some previous studies have shown that the screw profile could play an important role on the composite morphology. Investigations made by the Southern Clay Company have shown that a high shearing profile could lead to an exfoliated nanocomposite [18]. It was also noticed that the location of the shearing zones also had an influence on the final morphology. As a matter of fact, shearing zones should be located at the first zone of the profile to ensure exfoliation. In consequence, the screw configuration given by Fig. 1 was developed.

The main objective of this study is to achieve nanocomposite morphologies (intercalated or exfoliated) for montmorillonites, modified using ammonium ions without any polar group. Melt intercalation technique carried out using a pilot-scale twin-screw extruder with a selected screw profile was used. The influence on the mechanical properties and thermal stability of the PCL composite resulting to the incorporation of various organo-modified montmorillonites was also investigated.

\section{Experimental part}

\subsection{Materials}

Commercial grade poly( $\varepsilon$-caprolactone) (CAPA $\left.6800^{\circledR}\right)$ was purchased from Solvay Chemicals $\left(M_{\mathrm{w}}=80000, T_{\mathrm{m}}=60^{\circ} \mathrm{C}\right)$;

Commercial organo-modified montmorillonites (noted OMMT: Nanofil $5^{\circledR}$, Nanofil $2^{\circledR}$ ) were supplied by Süd-Chemie (Moosburg, Germany). Cloisite $30 \mathrm{~B}^{\circledR}\left(\mathrm{C} 3 \mathrm{~B}^{\circledR}\right)$ was supplied by Southern Clay Products. Nanofil $5^{\circledR}$ was modified with a dimethyl-distearyl ammonium, Nanofil $2^{\circledR}$ with dimethyl-stearyl-benzyl ammonium. $\mathrm{C} 3 \mathrm{~B}^{\circledR}$ was modified with methyl tallow bis-2-hydroxyethyl ammonium.

\subsection{Preparation of masterbatchesd}

A Haake RHEOMIX ${ }^{\circledR} 300$ internal mixer with two counterrotating rollers was used for the preparation of PCL/organoclay masterbatches at a clay percentage of $30 \mathrm{wt} \%$. The processing temperature was set at $140{ }^{\circ} \mathrm{C}$. The rotating speed of the rotor and the mixing time were respectively, $40 \mathrm{rpm}$ and $10 \mathrm{~min}$.

\subsection{Extrusion and injection moulding procedures}

PCL/organoclay nanocomposites were prepared using a Clextral BC21 co-rotating twin-screw extruder $(L=1200 \mathrm{~mm}, L / D=48)$.

The processing temperature was set at $140{ }^{\circ} \mathrm{C}$, the screw speed at $250 \mathrm{rpm}$ and the polymer flow at $3 \mathrm{~kg} / \mathrm{h}$. Clay percentages were 1 , 3 and $5 \mathrm{wt} \%$. The samples will be referred, respectively, as PCL1, PCL3 and PCL5. Dumbbell specimens were produced at $140{ }^{\circ} \mathrm{C}$ using a Sandretto Otto $95 \mathrm{t}$ injection moulding device.

\subsection{Characterization of composite morphology}

Morphologies were analyzed using a Bruker D8 diffractometer using $\mathrm{Cu} K_{\alpha}$ radiation. Data were collected between 1 and $13^{\circ}$ by step of $0.02^{\circ}$ using an X-ray generator with $\lambda=0.15406 \mathrm{~nm}$. Transmission electron microphotographs were obtained using a JEOL 1200EX2 apparatus with an acceleration voltage of $120 \mathrm{kV}$. Samples were $70 \mathrm{~nm}$ thick and prepared with a Leica Ultracut UCT ultra-microtome. One millimetre-thick samples were analyzed using a Rheometric Scientific (ARES ${ }^{\circledR}$ ) equipped with parallel plates. Each sample was analyzed at $140{ }^{\circ} \mathrm{C}$ in a frequency range from $10^{-1}$ to $10^{2} \mathrm{~Hz}$.

A Perkin-Elmer Diamond DSC differential scanning calorimeter was used to study crystallization processes. Samples were heated from $20^{\circ} \mathrm{C}$ to $100^{\circ} \mathrm{C}$ at $10^{\circ} \mathrm{C} / \mathrm{min}$ under nitrogen atmosphere and kept at $100^{\circ} \mathrm{C}$ for $1 \mathrm{~min}$. The cooling ramp was similar. The samples were then heated to $100{ }^{\circ} \mathrm{C}$ at $10{ }^{\circ} \mathrm{C} / \mathrm{min}$. The crystallization heat

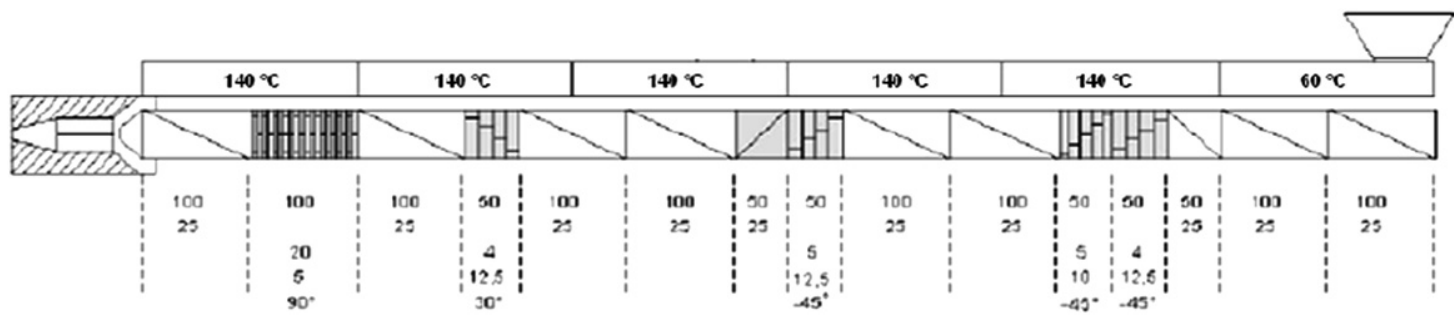

Fig. 1. Screw Configuration. 
was, after normalization to the samples mass, converted to PCL crystallinity according to equation (1):

$X_{\mathrm{c}}(\%)=\frac{\Delta H_{\mathrm{m}}}{W_{\mathrm{PCL}} \times \Delta H_{100}}$

where $\Delta H_{\mathrm{m}}$ is the measured value of melting enthalpy, $W_{\mathrm{PCL}}$ is the weight fraction of PCL in nanocomposite and $\Delta H_{100}$ is the enthalpy of melting $100 \%$ crystalline PCL (136.1 J/g) [16].

The values were recorded during the first heating scan. The crystallinity rate value is the average of three measurements.

\subsection{Thermal stability of composites}

TGA (Perkin-Elmer Pyris 1) was used to evaluate the thermal stability of nanocomposites. Samples were heated from $50{ }^{\circ} \mathrm{C}$ to $700{ }^{\circ} \mathrm{C}$ at a scan rate of $10{ }^{\circ} \mathrm{C} / \mathrm{min}$ under nitrogen at $20 \mathrm{ml} / \mathrm{min}$. Curves presented were the average of three measurements.

TGA coupled with FTIR was used to investigate the mechanisms of thermal degradation. IR spectra were measured using a Bruker IFS66-IR Spectrometer at room temperature, where 32 scans at a resolution of $4 \mathrm{~cm}^{-1}$ were signal averaged.

\subsection{Mechanical properties of composites}

Mechanical testing was performed using a ZWICK Z010 tensile test apparatus, at $20{ }^{\circ} \mathrm{C}$ at a constant rate of $1 \mathrm{~mm} / \mathrm{min}$ for Young's modulus determinations, according to the ISO 527-1 standard.

\section{Results and discussion}

\subsection{Analysis of clay dispersion by XRD}

Nanocomposites were analyzed by XRD in order to estimate the extent of clay dispersion in the PCL matrix.

XRD patterns for PCL nanocomposite filled with $3 \mathrm{wt} \%$ of Nanofil ${ }^{\circledR}$ are showed Fig. 2 . The interlayer distance for the organoclay is $18.5 \AA$. After melt blending with PCL, a peak was observed at $37 \AA$, showing that intercalated nanocomposites were obtained. A second peak was also observed at $4.2^{\circ}$ which indicates some ordering of the intercalated structure.

Fig. 3 shows XRD patterns for PCL nanocomposite filled with $3 \mathrm{wt} \%$ of Nanofil $5^{\circledR}$. The interlayer spacing for this organoclay is

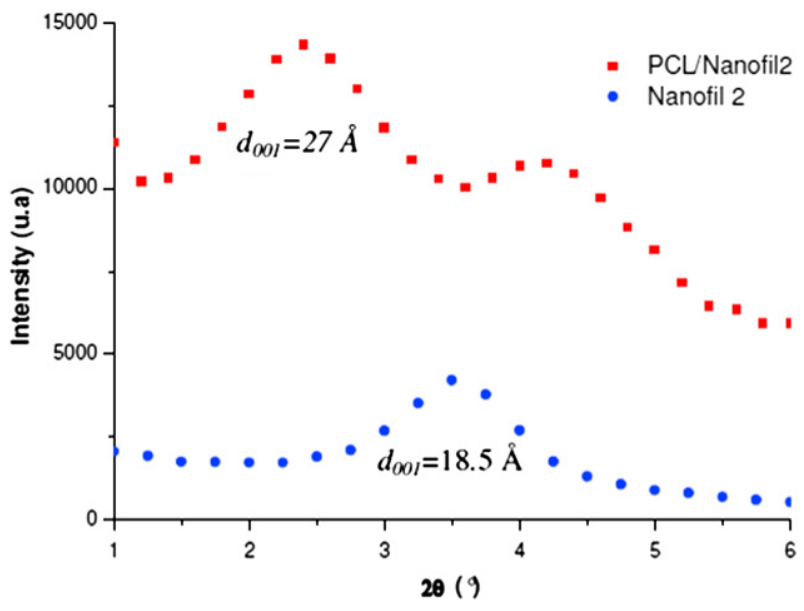

Fig. 2. X-ray scattering patterns of Nanofil $2^{\circledR}$ and PCL filled with 3 wt\% of Nanofil $2^{\circledR}$.

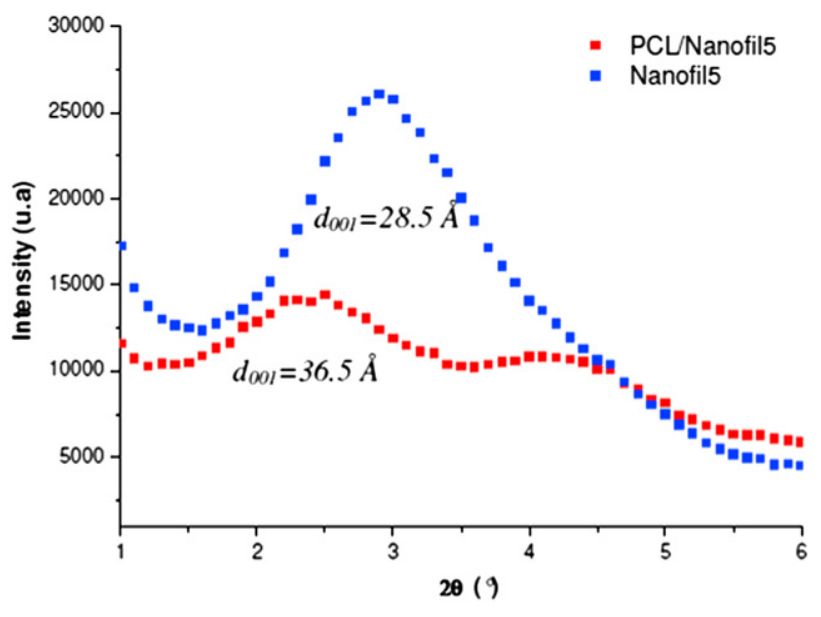

Fig. 3. X-ray scattering patterns of Nanofil $5^{\circledR}$ and PCL filled with $3 \mathrm{wt} \%$ of Nanofil $5^{\circledR}$.

$28.5 \AA$. For the nanocomposite, it is about $36.5 \AA$ proving that PCL chains were intercalated between layers.

For PCL nanocomposites filled with $\mathrm{C} 30 \mathrm{~B}^{\circledR}$, an intercalated/ exfoliated nanocomposite was obtained from XRD patterns, with an interlayer distance of $18 \AA$ in the organo-modified clay and $32 \AA$ in the composite (Fig. 4).

\subsection{Analysis of clay dispersion by TEM}

Nanocomposites were analyzed by TEM. Fig. 5 shows the filler dispersion and subsequent morphologies. For each one, nanocomposites with $3 \mathrm{wt} \%$ of clay were chosen to estimate the extent of filler dispersion.

Intercalated/exfoliated nanocomposites were obtained using for each composite containing the organo-modified clays. The dispersion seems not to differ slightly for the different organo-modified montmorillonites.

\subsection{Rheological properties}

Dynamic Mechanical analysis is a relevant tool to investigate the dispersion of modified clays. Dynamic strain sweep tests were applied to materials samples (Fig. 6). Dynamic viscosity $\left(\eta^{*}\right)$ of nanocomposites exhibited a Newtonian plateau at low strain

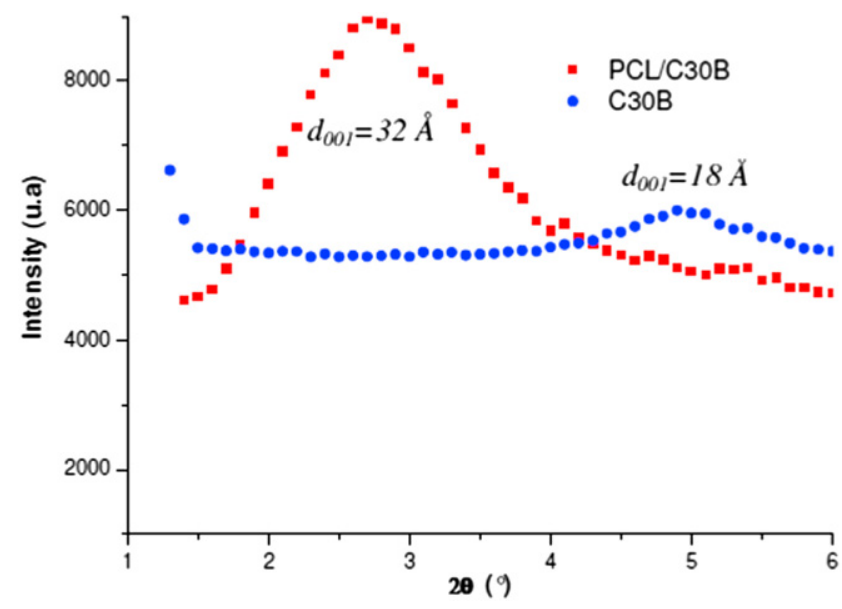

Fig. 4. X-ray scattering patterns of $\mathrm{C}^{3} 3 \mathrm{~B}^{\circledR}$ and PCL filled with $3 \mathrm{wt} \%$ of $\mathrm{C}^{\circledR 0 B}{ }^{\circledR}$. 

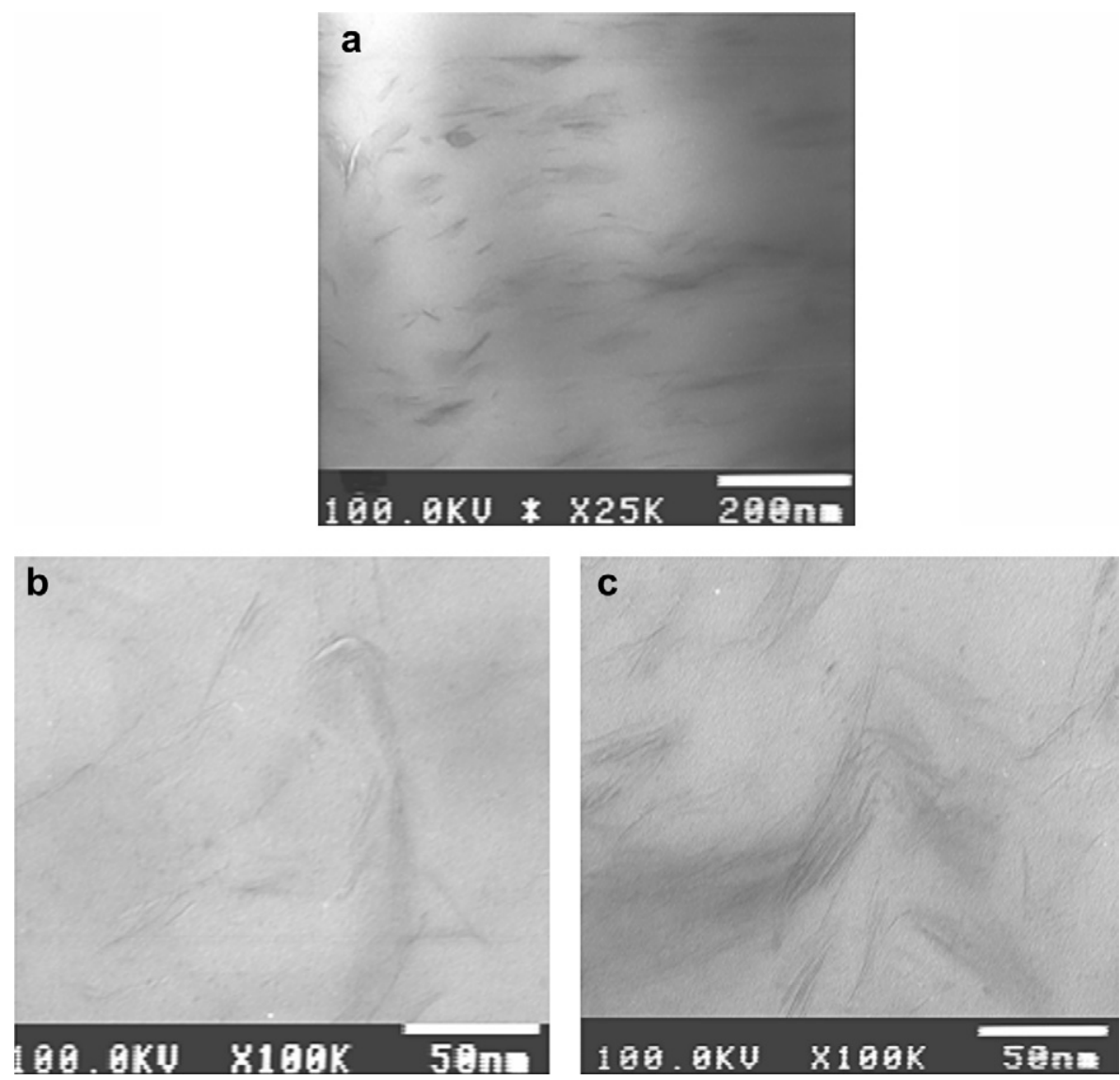

Fig. 5. Transmission electron microphotographs of PCL nanocomposites filled with 3 wt\% of: (a) Nanofill $5^{\circledR}$ (b) $C 30 B^{\circledR}$ (c) Nanofil $2^{\circledR}$.

(less than 10\%) and non-linear region at high strain amplitudes. For this study, we have chosen a strain $(\gamma)$ of $1 \%$.

Dynamic viscosity curves can be fitted by a power law model at low frequency zone. Several authors used dynamic viscosity to determine power law parameters at low frequencies [17]. Power law expression is written as follows equation (2):

$\eta^{*}=k \omega^{n}$

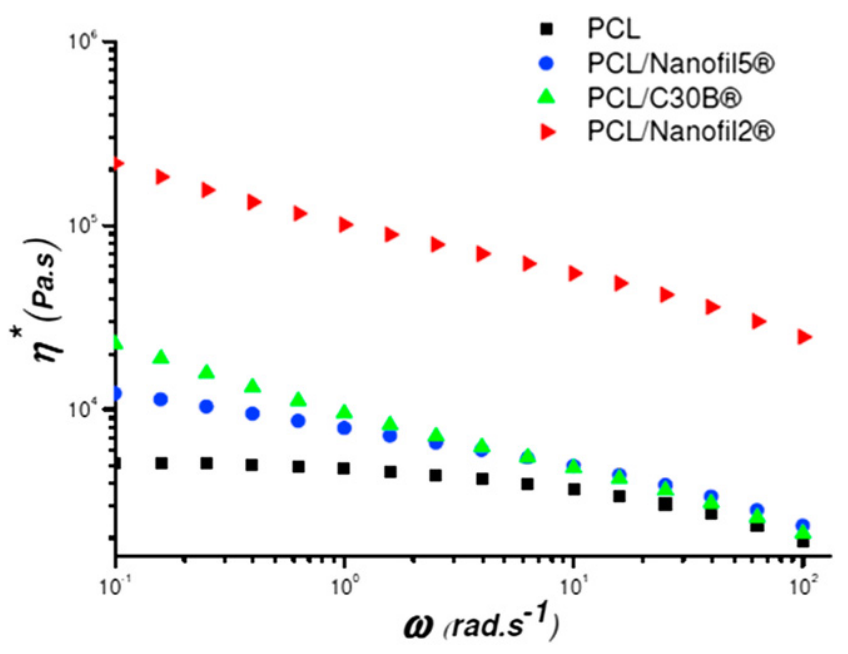

Fig. 6. Dynamic viscosity of PCL filled with $3 \mathrm{wt} \%$ of clay. where $\eta^{*}$ is the dynamic viscosity, $k$ is the sample specific exponential factor, $\omega$ is the oscillation frequency in the frequency sweep test and $n$ is the shear thinning exponent.

From equation (2), $n$ and $k$ could be determined from the logarithmic plot of dynamic viscosity vs. frequency $(\omega)$ equation (3):

$\log \left(\eta^{*}\right)=\log k+n \log (\omega)$

An increase of the dynamic viscosity at low frequencies gives us information about strong interfacial interactions between the polymer phase and the filler but no information is given about the dispersion state. However, the power law exponent, $n$, is expected to assess the extent of clay dispersion.

Shear thinning exponents, $n$, for different nanocomposites, are listed in Table 1. The more exfoliated samples would display a higher shear thinning exponent. Conversely, a limited exfoliation would lead only to a moderate shear thinning exponent.

It can be seen that $n$ values of $\mathrm{C} 30 \mathrm{~B}^{\circledR}$ and Nanofil $2^{\circledR}$ are higher than that of Nanofil $5^{\circledR}$. It could be considered that Nanofil $5^{\circledR}$ is less dispersed than $\mathrm{C} 3 \mathrm{~B}^{\circledR}$ and Nanofil $2^{\circledR}$ in the PCL matrix.

Table 1

Power law exponents.

\begin{tabular}{|c|c|c|}
\hline Samples & $-n$ & $R^{2}$ \\
\hline PCL & 0.025 & 0.886 \\
\hline PCL/Nanofill ${ }^{\circledR}$ & 0.412 & 0.993 \\
\hline $\mathrm{PCL} / \mathrm{C} 30 \mathrm{~B}^{\circledR}$ & 0.767 & 0.998 \\
\hline PCL/Nanofil $2^{\circledR}$ & 0.848 & 0.999 \\
\hline
\end{tabular}


Table 2

Crystallinity rate of PCL/Nanofil $2^{\circledR}$ nanocomposites.

\begin{tabular}{llll}
\hline Samples & Filler content $(\mathrm{wt} \%)$ & $\Delta H_{\mathrm{m}}(\mathrm{J} / \mathrm{g})$ & $X_{\mathrm{c}}(\%)$ \\
\hline Neat PCL & 0 & 71 & 52.1 \\
$\mathrm{PCL}_{1}$ & 1 & 69.2 & 51.4 \\
$\mathrm{PCL}_{3}$ & 3 & 68.1 & 51.6 \\
$\mathrm{PCL}_{5}$ & 5 & 67 & 51.8 \\
\hline
\end{tabular}

Since the viscosity of $\mathrm{PCL} / \mathrm{Nanofil} 2^{\circledR}$ appears significantly higher at low frequencies than that of $\mathrm{PCL} / \mathrm{C} 30 \mathrm{~B}^{\circledR}$, it seems indicate that a better dispersion has been achieved using a kind of organomodified MMT without any polar modifier, despite the polar character of PCL. This proved the efficiency of the screw configuration.

\subsection{Crystallinity and thermal stability}

DSC measurements (Table 2) indicate that the melting enthalpy, $\Delta H_{\mathrm{m}}$, seems not affected by the clay addition. The crystallinity rate decreases slightly from 52\% for virgin PCL to $51.4 \%$ for PCL filled with $1 \mathrm{wt} \%$ of Nanofil $2^{\circledR}$. Clay has consequently no significant nucleating effect.

The study of thermal degradation of organo-modified clays has shown that Nanofil $2^{\circledR}$ and Nanofil $5^{\circledR}$ present two similar weight losses respectively, at $200^{\circ} \mathrm{C}$ and $360^{\circ} \mathrm{C}$ for the first one (which is the less stable of the three clays) and at $230{ }^{\circ} \mathrm{C}$ and $340{ }^{\circ} \mathrm{C}$ for the second one (Figs. 7 and 8 ). Mass loss features indicated by TGA are confirmed by the number of peaks on Gram Schmidt patterns given by coupled FTIR analysis (not presented here).

Thanks to FTIR-TGA analysis, the first mass loss was identified and referred to $\mathrm{CH}_{2}$ elimination (2853 and $2928 \mathrm{~cm}^{-1}$ ), while the second degradation step was attributed to $\mathrm{CH}$ and $\mathrm{CH}_{3}$ elimination.

The second peak for Nanofil $2^{\circledR}$ (at $280{ }^{\circ} \mathrm{C}$ ) was attributed to the benzyl group elimination (at 1497 and $1475 \mathrm{~cm}^{-1}$ ).

Fig. 8 shows that the Cloisite $30 \mathrm{~B}^{\circledR}$ also exhibits two degradation steps. The first one, which correspond to the maximum degradation temperature, at $250{ }^{\circ} \mathrm{C}$, is similar to the first elimination for Nanofil ${ }^{\circledR}$ and $\mathrm{Nanofil}^{\circledR}{ }^{\circledR}$ (i.e. $\mathrm{CH}_{2}$ elimination). The second mass loss, at $380{ }^{\circ} \mathrm{C}$, is attributed to $\mathrm{OH}$ elimination (strong band at $3220 \mathrm{~cm}^{-1}$ ). The absorption around $2300-2400 \mathrm{~cm}^{-1}$ is ascribed to carbon dioxide (Fig. 9).

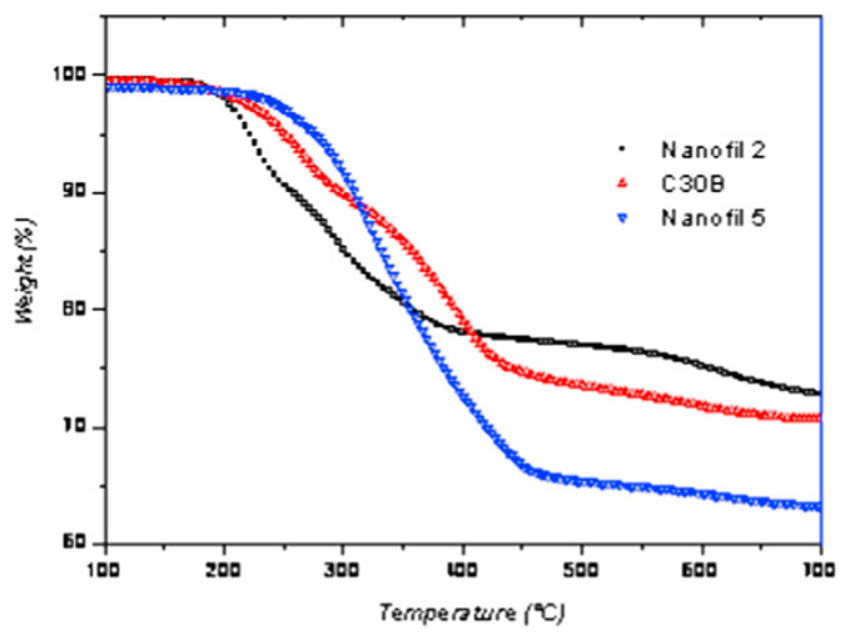

Fig. 7. TGA different nanofillers under nitrogen atmosphere at $10{ }^{\circ} \mathrm{C} / \mathrm{min}$ temperature rate.

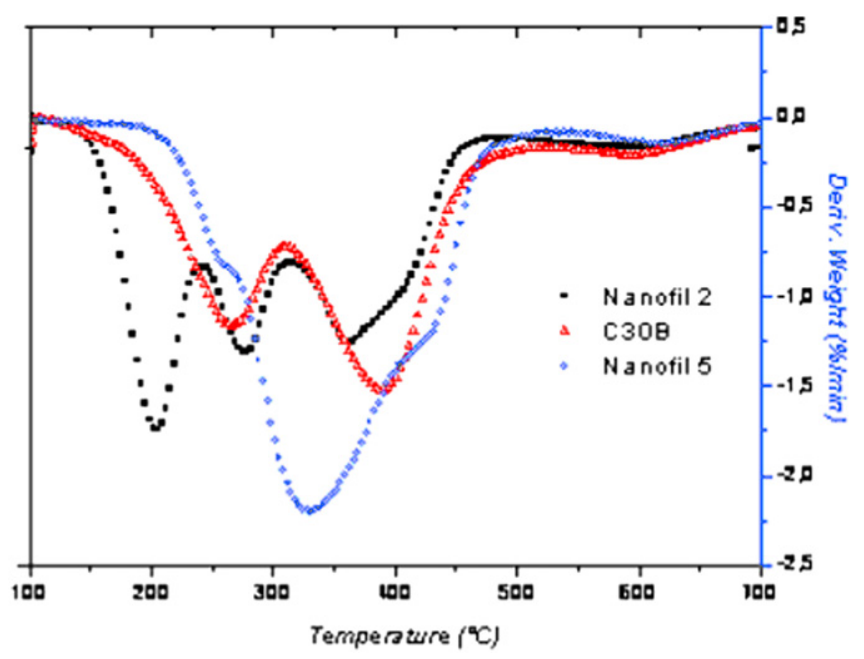

Fig. 8. DTG of different nanofillers under nitrogen atmosphere at $10{ }^{\circ} \mathrm{C} / \mathrm{min}$ temperature rate.

These data allows us to propose degradation reactions for each alkyl ammonium modifier (Figs. 10, 11 and 12).

Investigations about thermal degradation of virgin PCL have shown that two degradation steps occurs [19]. The first step (near $380{ }^{\circ} \mathrm{C}$ ) is characterized by the departure of the hex-5-enoic acid (random chain cleavage via cis-elimination) followed by unzipping (up $400{ }^{\circ} \mathrm{C}$ ). From our TGA experiments under nitrogen, only one mass loss step for can be noticed for the PCL and the nanocomposites (Fig. 15). Moreover, for all materials, no significant residue can be observed at $500{ }^{\circ} \mathrm{C}$. Despite the low percentage of clay introduced in PCL, strong differences can be noticed for the thermal degradation behaviour of nanocomposites in comparison with the virgin polymer. $\mathrm{PCL} / \mathrm{C} 30 \mathrm{~B}^{\circledR}$ nanocomposite is less stable than PCL. As mentioned before, the decomposition of $\mathrm{C}^{30 \mathrm{~B}^{\circledR}}{ }^{\circledR}$ leave hydroxyl groups which could give water molecules (Fig. 12), able to hydrolyze the $\varepsilon$-caprolactone to produce hex-5-enoic acid, which can then accelerate PCL decomposition [19].

The nanocomposites containing the clays without polar modifier exhibit the highest thermal stability, but only up to $375^{\circ} \mathrm{C}$ for Nanofil $5^{\circledR}$. It can be suggested that the very high interfacial area between montmorillonite and polymer for intercalated/exfoliated morphologies could produce a physical barrier effect, able to strongly decrease the diffusion of volatile products released by the

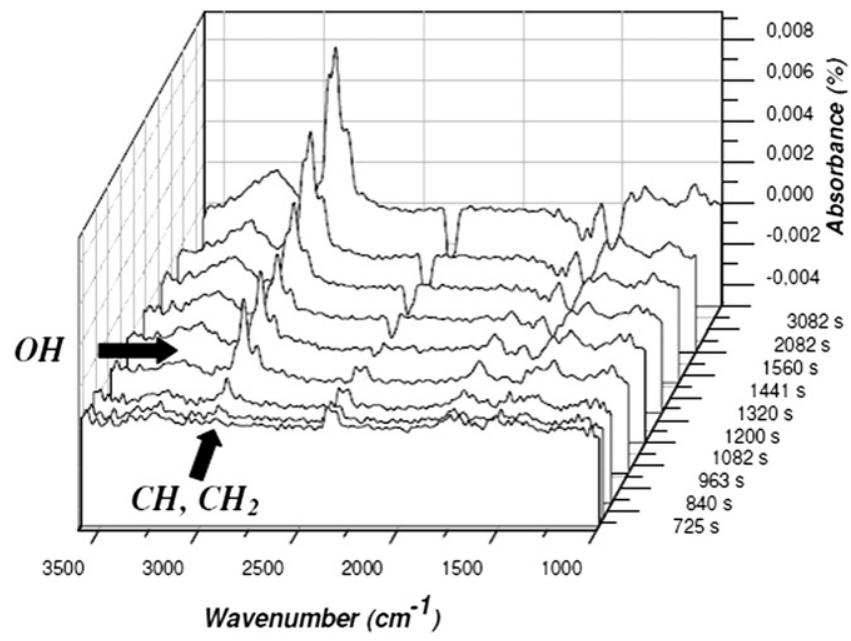

Fig. 9. Dynamic FTIR spectra of $C 30 B^{\circledast}$ in function of time. 


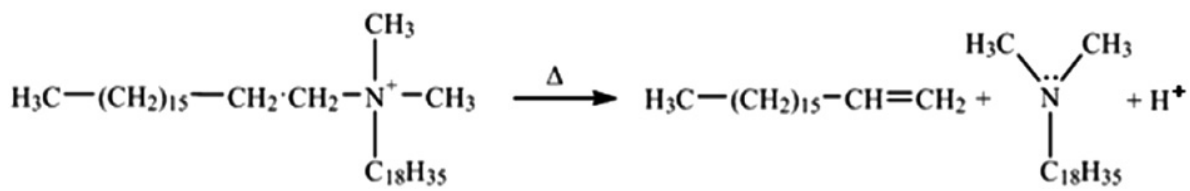

Fig. 10. Possible decomposition reaction of Nanofil $5^{\circledR}$.

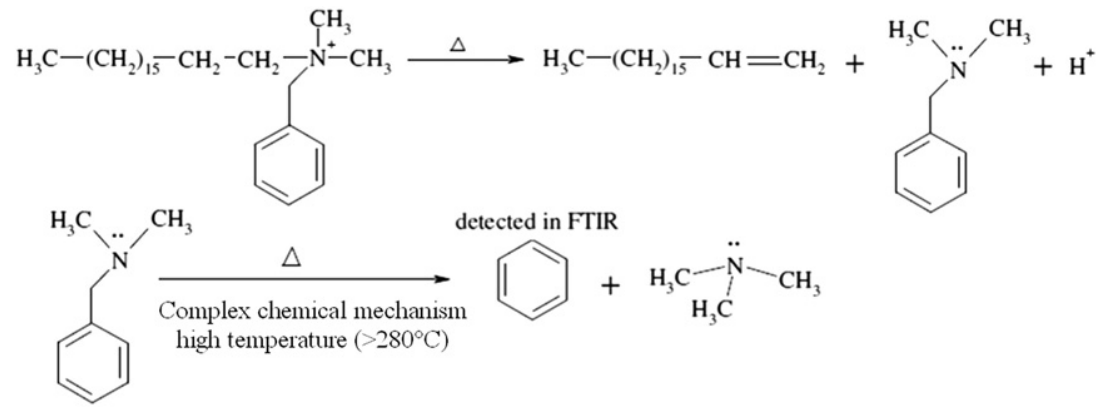

Fig. 11. Possible decomposition reaction of Nanofil $2^{\circledR}$.

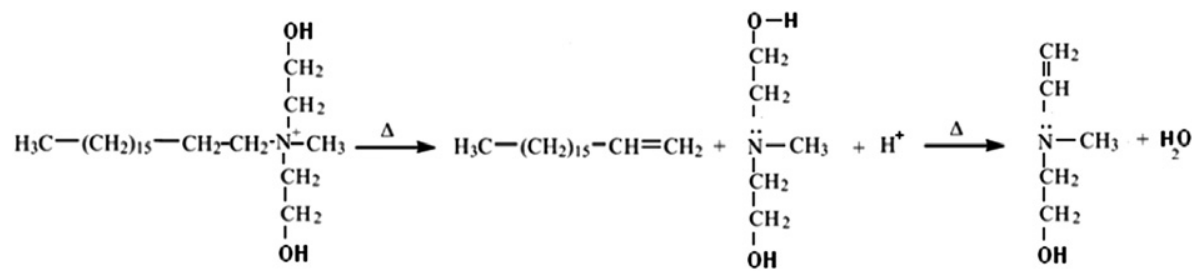

Fig. 12. Possible decomposition reaction of $\mathrm{C} 3 \mathrm{~B}^{\circledR}$.

materials. At higher temperatures than $375^{\circ} \mathrm{C}$, differences can be noticed between PCL/Nanofil2 and PCL/Nanofil5. Paradoxically, the degradation of the first one occurs at higher temperatures, whereas the corresponding organo-modified clay is less stable.

This could be explained by the catalytic activity of clays after their thermal degradation involving the mechanisms proposed above (Figs. 10-12). The formation of acidic clays is able to generate a strong catalytic activity, which can be higher for Nanofil $2{ }^{\circledR}$, due to its lower degradation temperature, its better initial dispersion in

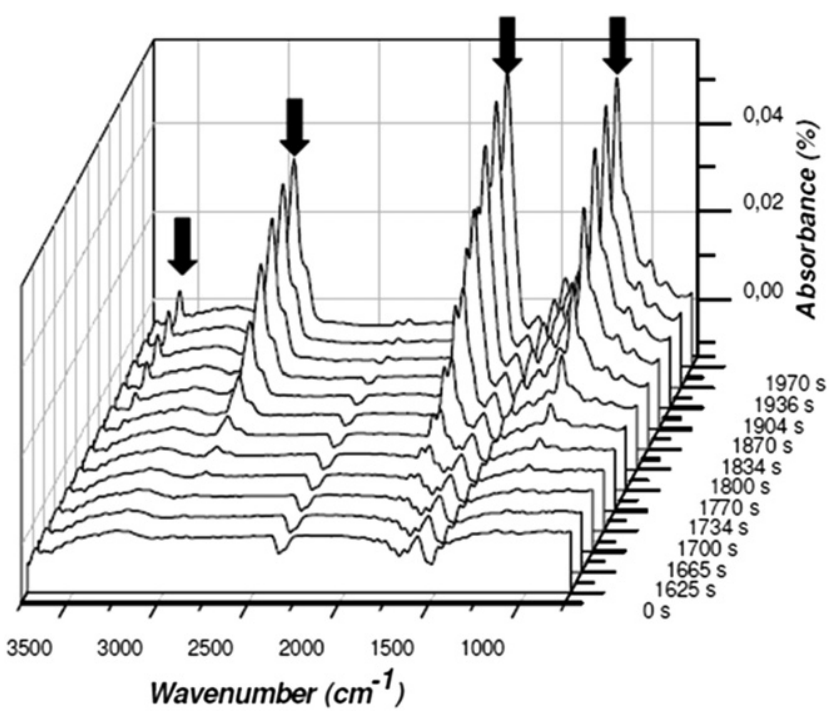

Fig. 13. Dynamic FTIR spectra of $\mathrm{PCL} / \mathrm{C} 30 \mathrm{~B}^{\circledR}$ nanocomposites in function of time. the matrix, and also due to the higher clay content in the remaining material.

FTIR spectra of PCL nanocomposites display four broad absorptions (Figs. 13 and 14). The first strong band at $1771 \mathrm{~cm}^{-1}$ is due to the carbonyl function of the carboxylic acid in the gas phase, produced by pyrolysis of the PCL ester functions. Moreover, the additional intense absorption centered on $1736 \mathrm{~cm}^{-1}$ is ascribed to the $\varepsilon$-caprolactone. The peak at $1200 \mathrm{~cm}^{-1}$ is attributed to $\mathrm{C}-\mathrm{O}$ stretch vibration of acid group. Finally, the adsorption band from 2850 to $3020 \mathrm{~cm}^{-1}$ is assigned to $\mathrm{CH}$ and $\mathrm{CH}_{2}$.

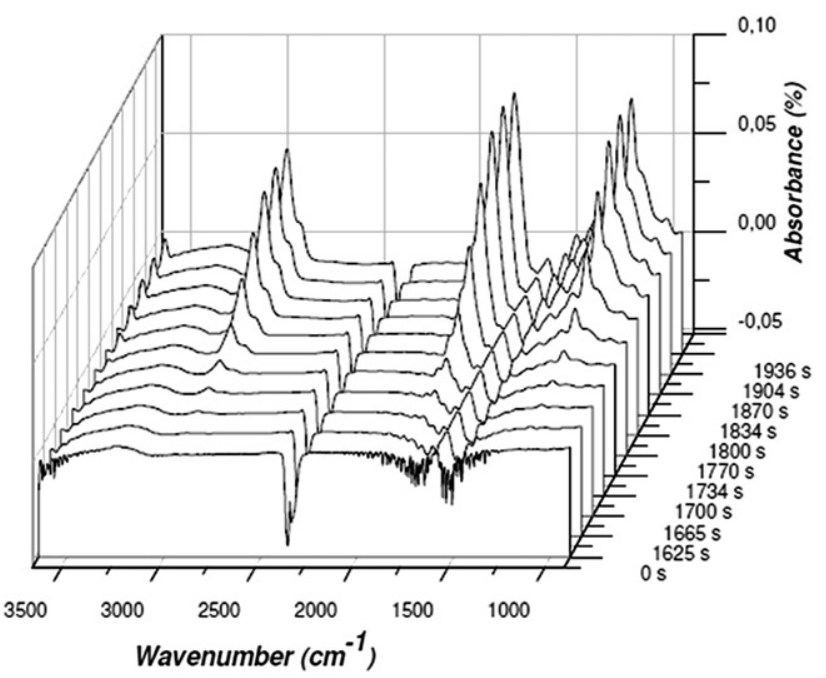

Fig. 14. Dynamic FTIR spectra of PCL/Nanofil ${ }^{\circledR}$ nanocomposites in function of time. 


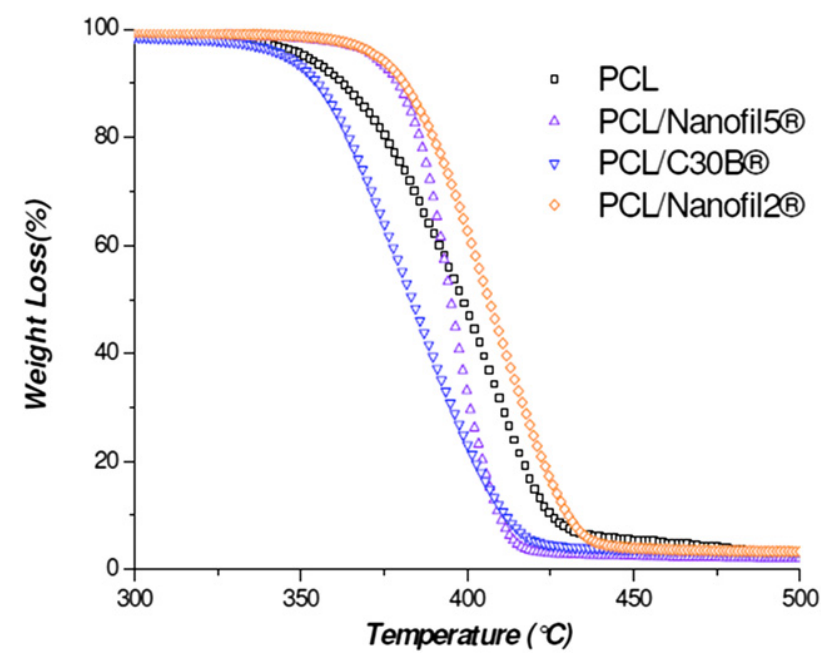

Fig. 15. TGA of PCL filled with $3 \mathrm{wt} \%$ of clay under nitrogen atmosphere at $10{ }^{\circ} \mathrm{C} / \mathrm{min}$ temperature rate.

Decarboxylation of hex-5-enoic acid or other carboxylic acid can lead to carbon dioxide (band around $2300-2400 \mathrm{~cm}^{-1}$ ). Water band is also detected at $3620 \mathrm{~cm}^{-1}$ and may result from the condensation of hydroxyl groups for PCL/C30B.

Whatever the nature of composite, all the peaks appear at the same time in Figs. 13 and 14 (except that of water). Nevertheless, their magnitudes are lower for PCL/Nanofil2 in comparison with PCL/C30B.

\subsection{Mechanical properties}

Mechanical properties of nanocomposites depend on many factors, including, the amount of the filler, clay dispersion and adhesion between filler and matrix.

Fig. 16 shows Young's modulus for the different nanocomposites. It increases with clay incorporation in comparison to the virgin PCL and strongly depends on the clay amount and its nature. The highest value for a percentage of $1 \mathrm{wt} \%$ is obtained for Nanofil $2{ }^{\circledR}$ and this can also be ascribed to a better dispersion. At this very low percentage of organo-modified clays in the matrix, one can notice that the highest modulus values correspond to the clays containing only modifiers with non-polar chains.

Regardless the nature of modified clay, the tensile modulus is increased twice at a percentage of only $5 \mathrm{wt} \%$, in comparison to the virgin matrix.

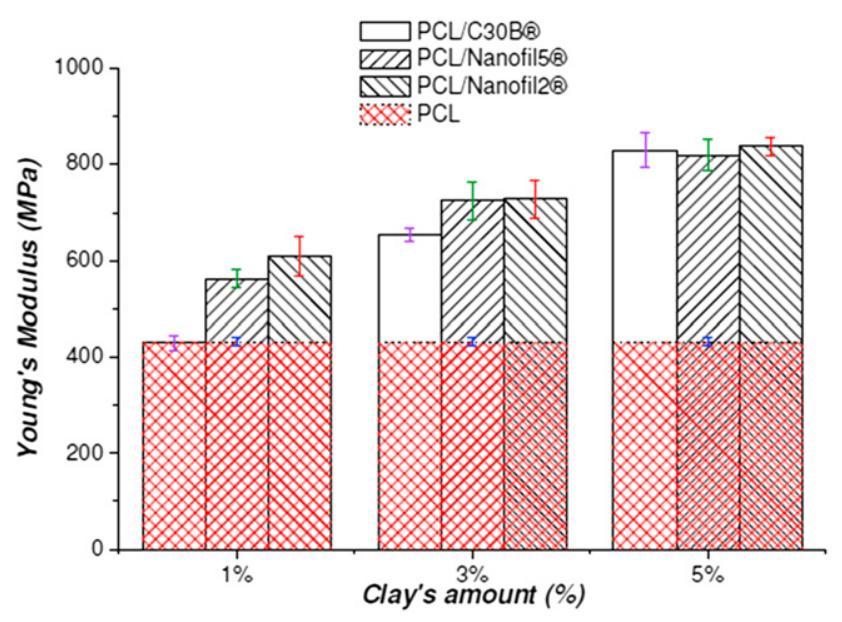

Fig. 16. Young's modulus of different nanocomposites.

\section{Conclusions}

Three commercial montmorillonites, Nanofil $5^{\circledR}$, Nanofil $2^{\circledR}$ and Cloisite $30 \mathrm{~B}^{\circledR}$ were used to prepare organo-modified montmorillonite/poly( $\varepsilon$-caprolactone) composites by melt intercalation. A twin-screw extruder with a specific screw profile was designed in order to promote the formation of nanocomposites. Clay dispersion was investigated by XRD, TEM and rheological behaviour of samples. All techniques showed exfoliated/intercalated morphologies and rheological tests and highlighted a better dispersion degree for Nanofil $2^{\circledR}$.

Owing to the selection of the screw profile, nanocomposite morphology was achieved in this study, regardless of the polar (Cloisite $30 \mathrm{~B}^{\circledR}$ ) or non-polar nature of the alkyl chains of the clay modifier.

The incorporation of organo-modified clays allowed the thermal stability to be improved in comparison with the virgin PCL. However, due to PCL hydrolysis caused by the presence of hydroxyl groups in the modifier, a lower thermal stability was noticed for Cloisite $30 \mathrm{~B}^{\circledR}$ composition in comparison with that of Nanofil $2^{\circledR}$, which modifier contains only non-polar groups, and which seems to create a better barrier effect and promotes catalytic activity due to its acidic surface after its own thermal degradation.

Young's modulus was also significantly increased by the incorporation of the organo-modified clays. The marked increase of Young's modulus is ascribed to the high degree of dispersion and the relatively low value of residence time using twin-screw extrusion, in comparison with the processing techniques used in previous studies, which could entail PCL thermal degradation during the processing stage.

\section{Acknowledgements}

We would like to thank Mrs. Sonia PERNA from Süd-Chemie. We are also indebted to Marc LONGEREY for his assistance about rheological measurements.

\section{References}

[1] Alexandre M, Dubois P. Materials Science and Engineering 2000;28:1-63.

[2] Usuki A, Hasegawa N, Kato M. Polymer-clay nanocomposites. Polymer 2005;179:135-95.

[3] Homminga D, Goderies B, Dolbnya I, Groeninkx G. Polymer 2006;47:1620-9.

[4] Jimenez G, Ogata N, Kawai H, Ogihara T. Journal of Applied Polymer Science 1997;64:2211-20.

[5] Chrissafis K, Antoniadis G, Paraskevopoulos KM, Vassiliou A, Bikiaris DN. Composites Science and Technology 2006;67:2165-74.

[6] Lepoittevin B, Devalckenaere M, Alexandre M, Calberg C, Jérôme R, Dubois P. Polymer 2003;44:2033-40.

[7] Karaman VM, Privalko EG, Privalko VP, Kubies D, Puffr R, Jérôme R. Polymer 2005;46:1943-8.

[8] Pollet E, Delcourt C, Alexandre M, Dubois P. European Polymer Journal 2006;42:1330-41.

[9] Lepoittevin B, Devalckenaere M, Pantoustier N, Alexandre M, Kubies D, Calberg C, et al. Polymer 2002;43:4017-23.

[10] Di Maioa E, Iannaceb S, Sorrentinob L, Nicolais L. Polymer 2004;45:8893-900.

[11] Perez CJ, Alvarez VA, Vazquez A. Materials Science and Engineering A 2008;480:259-65.

[12] Kiersnowski A, Dabrowski P, Budde H, Kressler J, Pigłowski J. European Polymer Journal 2004;40:2591-8.

[13] Zheng X, Wilkie CA. Polymer Degradation and Stability 2003;82:441-50.

[14] Ludueña LN, Alvarez VA, Vazquez A. Materials Science and Engineering A 2007;460-461:121-9.

[15] Homminga D, Goderis B, Hoffman S, Reynaers H, Groeninckx G. Polymer 2005;46:9941-54.

[16] Kiersnowski A, Pigłowski J. European Polymer Journal 2004;40:1199-207.

[17] Wagener R, Reisinger TJG. Polymer 2003;44:7513-8.

[18] Southern clay products presentation, Product Commercialization One Nanostep at a Time, Texas (USA), Oct 2006.

[19] Persenaire O, Alexandre M, Degee P, Dubois P. Biomacromolecules 2001;2: 288-94. 